\title{
Importance of Culture for Sustainable Development
}

Mitja Bervar

мв zavod, Slovenia

mitja.bervar@gmail.com

Anita Trnavčević

University of Primorska, Slovenia

anita.trnavcevic@fm-kp.si

The aim of this paper is to investigate the importance and the role of culture in sustainable development. The study is based on a qualitative research on the quota sample of three referential groups of experts by using interview as a method of data collection. The findings of the study confirm that culture, as a holistic and complex system of values and creative potentials, stimulates social cohesion in society, strengthens intercultural dialogue as well as provides for economic effects, all of which is in turn reflected in sustainable development. We suggest the establishment of a fourth pillar, aside the economic, social and environmental, to be incarnated by culture. Key Words: sustainability, culture, social cohesion, intercultural dialogue, fourth pillar

JEL Classification: D63, E61, L38, Z10

https://doi.org/10.26493/1854-6935.17.195-209

\section{Introduction}

Sustainability is one of the key concepts in the European Union. It has been devoted the whole decade but recently more and more events reposition sustainability at the center of political issues and theoretical discussions. Greta Thunberg and her call that young people need home in the future - the Earth. Theoretically, in all areas of sustainable development on going publications in the field of environmental sciences, economy, and social sciences show the need for researchers to provide data for decision-makers. In political arena, sustainability and sustainable development are on the agenda of every major world summit, and also 'locally' at the level of nation states and local communities.

Sustainability is defined in the Brundtland Report as 'development that meets the needs and aspirations of the present without compromising the ability of future generations to meet their own needs' (United Nations World Commission on Environment and Development 1987, 43). 
Sustainable development has been commonly defined from the perspective of three interrelated dimensions, namely the economic, social and environmental (Kates, Parris, and Leserowitz 2005; Hasna 2007; Elliott 2013; Kordestani, Peighambari, and Foster 2015; Sachs 2015). In practice, sustainable development means searching for, debating and seeking compromise among different concepts and set priorities according to our value system, like the triple-bottom-line concept (3B L) and ecologically sustainable development concept (ESD) (Utting 2000; Savitz 2014; Apte and Sheth 2016).

A traditional conceptual framework of sustainable development has been lately expanded by the fourth pillar: culture (Hawkes 2001) thus recognizing the importance of cultural sustainability. In the European Union, the value system aspires sustainability. The debate about values in the past two decades, when Europeans have broadly embraced the concepts of sustainable development, has been a cultural debate. Namely, 'cultural vitality is as essential to a healthy and sustainable society as social equity, environmental responsibility and economic viability' (Hawkes $2001,7)$. Hence, social dimension of sustainable development is not sufficient to provide holistic view on sustainable development.

In the past, the role of culture on society development was largely ignored. Nowadays, that view has been changing as an extraordinary range of potential benefits of the concept of culture, like cohesion, engagement, belonging and distinctiveness, are being integrated into frameworks of sustainable development (Hawkes 2001, Segalas et al. 2009; Makarov 2010; Li in Pak 2010; Singer 2010; Shaharir 2012).

The new governance paradigm of four building blocks of sustainability, namely economic wellbeing, environmental harmonization, social justice and cultural vitality as basic requirements, can provide a final goal of any responsible policy resulting in a sustainable society (Lee 2016). In this respect, 'culture is not the decoration added' (Hawkes 2001,3) to basic needs of any society, but itself is the basic need.

It is the imperative that we include the concept of culture as a co-creator and promoter of sustainable development in terms of intercultural and interreligious dialogue in the society. Those partial solutions should give way to more comprehensive, holistic understanding and embracement of sustainability (UNESCO 2001; 2010; 2013). We need to incorporate cultural dimension, culture in action, into the concept of sustainable development as the fourth dimension due to interdependency of sustainable development and culture. The aim of this paper is to explore the impor- 
tance and the role of culture in sustainable development in the framework of European policies. The study is based on a qualitative research on the purposive sample of three referential groups of experts by using interview as a method of data collection.

\section{Culture as the Fourth Pillar of Sustainability}

Sir Edward B. Tyler, British anthropologist, provided already in 1871 a definition of culture as the complex whole which includes knowledge, belief, art, morals, law, custom, any other capabilities and habits acquired by man as a member of society. His work gave first outlines of a new discipline, known as culturology.

Culture is an all-embracing concept that refers to the way of life of individuals in a particular society. Culture is who we are and no development can be viable in long-term without culture (Frantzeskaki, Loorbach, and Meadowcroft 2012; United Nations 2012; UNESCO 2005; 2013).

In 1998, intergovernmental conference on cultural policies for development took place in Stockholm on the premise of 'culture being understood as the basis of development, the very notion of cultural policy has to be considerably broadened' (UNESCO 1998). The conference recognized twelve principles and placed the culture at the very center of long-term development policies, among others the interdependence of sustainable development and culture, cultural fulfillment of people, involvement in cultural life, dialogue between cultures, cultural creativity, cultural diversity and cultural pluralism, and creativity in societies (UNESCO 1998). Moreover, the conference adopted several policy objectives as a recommendation to governments worldwide while designing, promoting and implementing their long-term, i.e. sustainable development strategies.

The concept of culture has been embedded in, and enhancing, the paradigm of society of values and the very concept of sustainable development. Only sustainable culture shows needed vitality for enabling sustainable society. Therefore, the fourth pillar - cultural sustainability is the glue that binds society. (Hawkes 2001).

A framework of sustainable development based on four pillars of sustainability: economy (material well-being through sustainable economic growth), equity (social well-being though social cohesion), ecology (environmental well-being through natural harmonization) and culture (cultural well-being through intercultural dialogue) is proposed (figure 1).

Hence, four pillars of sustainability have to become formally adopted around the globe: environmental sustainability, social sustainability, eco- 


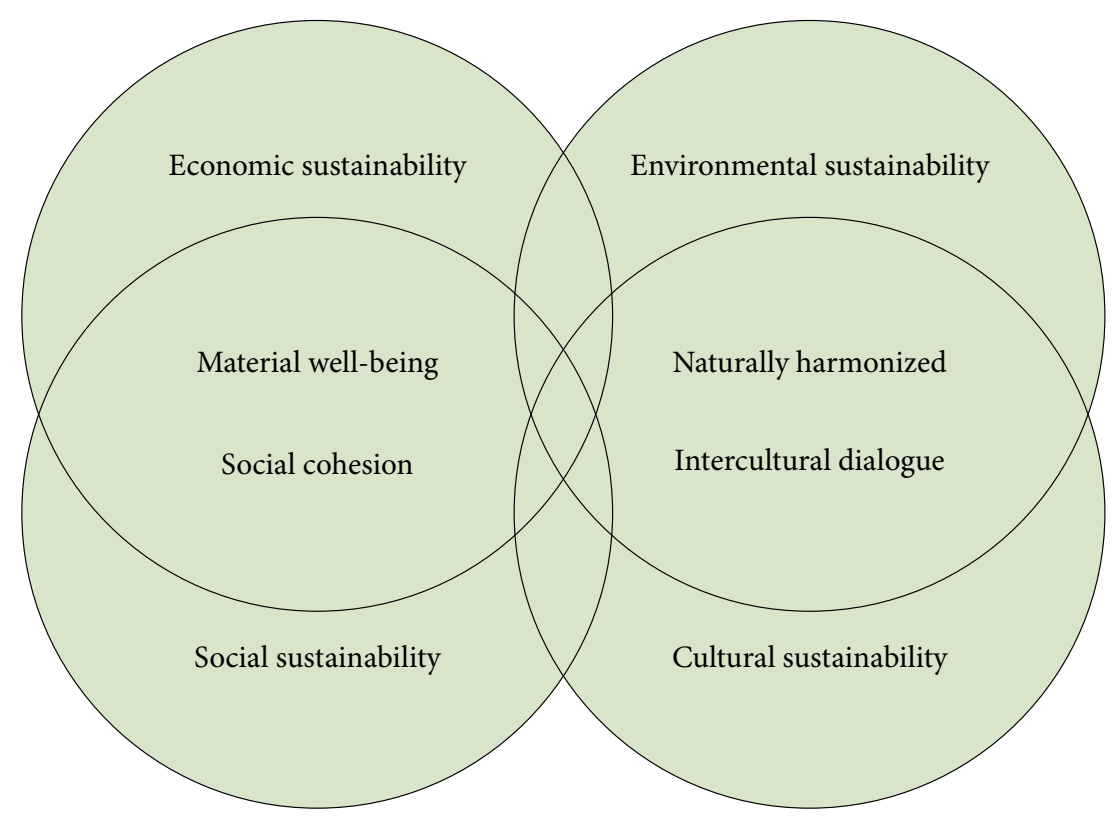

FIGURE 1 Four Pillar Concept of Sustainability

nomic sustainability and cultural sustainability (Yencken and Wilkinson 2000).

\section{CULTURE AS PROMOTER OF INTERCULTURAL DIALOGUE}

Intercultural dialogue, in its essence, 'seeks linkages and common ground between different cultures, communities, and people, promoting understanding and interaction' (European Commission 2008).

A precondition for promoting intercultural dialogue and bringing communities together is a commitment of all stakeholders for full cooperation and openness to cultural diversity and dialogue in order to avoid conflicts. In this respect, media has an important meditating role in intercultural dialogue as it not only greatly influences what we think, but also how we act. The use of information and communication technology (IC T) enables different cultures to interact with the contemporary world, to express themselves on their own terms and, hopefully, advance mutual knowledge, understanding and tolerance (Yarbrough 2011; Joyce, Vincze, and Marton 2016).

Culture plays an important role in the process of integrating migrants (Kearns and Whitley 2015; Ucok-Sayrak 2016), to help them better under- 
stand interactions with their new socio-cultural environment, thus contributing to more cohesive society by avoiding the tenacity of prejudice. Intercultural dialogue is a corrective to the diversity of our cultural intolerance and stereotypes on one side, but involves cultural tensions between people and communities on the other side when values and collective memory are involved (Human Rights Council 2007).

So what went wrong with the intercultural dialogue in the past? According to Schoefthaler (2006), intercultural dialogue has largely failed because of its focus on what is 'in common' rather than on differences and diversity. Mutual tolerance and respect rather than mere acceptance of diversity is needed (Schoefthaler 2006). According to the United Nations avoiding the deepening of existing stereotypes is the preferred way, all cultures should receive equal dignity. World of the 21st century is becoming increasingly multicultural. According to Huntington (1993 22), 'the great division among humankind and the dominating source of conflict will be cultural. The 'clash of civilizations' will dominate world politics. Or alternatively, the co-existence will prevail as different civilizations as cultural entities will have to learn how to live with the others. A shift from clash toward alliance of civilization is needed.

Intercultural dialogue is dependent on intercultural competencies, defined as 'complex of abilities needed to perform effectively and appropriately when interacting with those who are linguistically and culturally different from oneself' (Fantini 2007). In an intercultural dialogue, three basic capabilities are required to be efficient, namely listening capability, dialogue capability and wonder capability (Eberhard 2008).

Several new initiatives for intercultural and interfaith dialogue have been started in recent years. According to Eberhard (2008) the engagement in the process of dialogue should include our basic abilities to listen, wonder and dialogue.

\section{IMPORTANCE OF CULTURE FOR SOCIAL COHESION}

Social cohesion is commonly defined as the glue that keeps societies together. The European Union has experienced the challenges of not only economic globalization but also cultural globalization. In addition to more recent mass migration concerns and security threats, both having an (negative) impact on the stability of the society. The issue of social trust has emerged along with the need to be measured over time (Larsen 2014).

A modern globalized and multicultural world is also a world full of 
economic and financial crises. As a similarity of mind is difficult to achieve, it should at least be cultivated. Hence, culture can help in times of increased interdependence by promoting values of social inclusion and the idea of non-discrimination, tolerance and respect for diversity (Throsby 1999; Sage 2013; Mulunga and Yazdanifard 2014; Marrion 2016). Promotion of economic and social cohesion should be one of the priorities that guide our activities (Commission of European Communities 1994; Throsby 2001; Bueno, Salmador, and Rodríguez 2007; Brad et al. 2016). The EU's cohesion policy aims to help regions with the EU structural funds to achieve their full potential in order to bring about a convergence of living standard and prosperity and to reduce regional disparities (European Commission 2001; 2008; 2009 and 2011; OECD 2011; Støvring 2012; Wells in Lixinski 2016).

'The concept of culture provides the intellectual tools with which a more effective structure can be build' (Hawkes 2001, 1). A range of concepts that have developed in parallel, can be brought together and developed further, including the concept of cohesion and socially-held values (sense of purpose and meaning). Cultural diversity is essential component of social cohesion (coexistence) and economic cohesion (prosperity). Both, cultural and economic inequities need to be addressed, cultural democracy will have to occur. 'Cultural capital is the glue that holds a society together, social capital is the lubricant that allows it to operate smoothly' (Hawkes 2001, 18).

Economic development can be seen as a window of opportunity to increase social cohesion, but in itself it is not a sufficient condition (Larsen 2014). Social trust and multicultural dialogue are also needed for social integration and social cohesion. European union seeks for common policies on sustainable development however there are numerous questions and issues that need to discussed, dialogued and resolved at the nation states' levels and under national jurisdiction. Although, generaly speaking, there is basically no political person speaking against sustainable development in European Union there are varieties of solutions and understandings how sustainable development needs to be implemented. In Slovenia, there has not been a study that would engage the experts from different areas on issues related to cultural sustainability.

\section{Research Methodology}

Qualitative research approach (Yin 1984) was selected to execute the study of cultural sustainability in Slovenia as we wanted to gain insight 
into the personal understanding of the research problem by policy makers, experts and executive managers, thus focusing on studying the subjective meaning that selected participants attributed to the studied aspect of culture sustainability.

Quota sampling was used as a method for selecting participants based on their professional experience and knowledge in relation to the research problem. Participants were segmented into three homogeneous groups and semi-structured interviews (Galletta and Cross 2013) were conducted, each lasting from 60 to 90 minutes. The interview protocol was comprised of 20 questions divided into 2 sections. The interviews were tape recorded with participants' consent and transcribed. Participants were properly anonymized.

First group of participants in the study was comprised of five executive managers with the long-term experience and/or good knowledge and support of the culture sector.

Second group of participants in the study was comprised of six experts with the long-term experience in program planning, education, cultural heritage advisory, non-governmental organizations, authors' rights segment, management of public arts organization.

Third group of participants in the study was comprised of five policy makers, including three former ministers for culture, counsels and members of the national council for culture.

\section{RESEARCH QUESTIONS}

The following research questions were framed for the study:

1. What importance participants in the study give to culture as a fourth building block of sustainable development?

2. How do participants in the study describe importance of culture for social cohesion?

3. How do participants in the study describe importance of culture for intercultural dialogue?

\section{Results and Discussion}

PARTICIPANT OPINION ON IMPORTANCE OF CULTURE FOR SUSTAINABLE DEVELOPMENT

The responses of participants that attempted to identify the aspects with which culture contributed to the sustainable development of society were multifaceted. No participant expressed the opinion that culture does not 
contribute to sustainable development, and one even stated that culture in the broadest sense is crucial for understanding the importance of sustainable development. They emphasized that culture, as the bearer of identity in society, creates a system of values that it is a social binder to promote creativity and innovation at different levels of life, to promote social criticism and open spaces of dialogue, and to carry the potential of conflict prevention in itself, as it helps to break down tensions at the symbolic level.

At the same time, the participants warned about the need to search for added value, synergistic effects in linking culture with other fields. They expressed themselves critically about the lack of political will or competence of political decision-makers to place culture in the development strategies, as well as about high passivity of stakeholders in the field of culture, which would place responsibility for it too much in the hands of politics, depending on funding. They also warned that culture, in the absence of an imminent system of values, can also mean a security threat, a threat to the devastation of civilization, and warn against the instrumentalization of culture.

Participants recognized in the culture the potential for identity enhancement, the promotion of a creative, innovative and inclusive society, openness to the difference, recognized it a preventative role in preventing future financial and social crises, an important role in health prevention, and even in preventing conflicts and security risks. They linked it with social development, and recognized it as a 'generator of creativity' and a prerequisite for social cohesion.

The participants answered that cultural capital is the materialization of creativity and acquired knowledge. It is the result of a long-lasting development of society and contains a wealth of cultural heritage of nations or the global community. According to the interlocutors, cultural capital is an imminent component of the developmental level of society, and at the same time it is a strong anchorage of the individual in the community. Some people perceive this individual as the greatest cultural capital. Participants also mentioned the link between cultural and social capital and the level of tolerance in society.

PARTICIPANT OPINION ON CULTURE AS A PROMOTER OF SOCIAL COHESION

The study shows that almost all participants are well acquainted with the field. They have been actively involved in cultural projects in their per- 
sonal or business life in order to promote social cohesion. The general belief of participants is that culture is a strong community binder. In this context, they draw attention to its inclusive nature, which enables cultural institutions to become places of dialogue and confront with differences, a culture of the inclusion of the inclusive society and the quality of life in it. Accessibility of culture and active participation in it strengthens the individual's image, allows him to travel from the margin and gives a sense of inclusion, acceptance. It can therefore also be a powerful factor of the prevention on area of health and safety.

According to our interlocutors, social cohesion is created when people are exposed to the common experience that connects them. Although modern democracy and a lifestyle at the global level enable less of this kind of experience, amateur culture throughout the Slovenian cultural space lives an intense life and is established as a strong connecting element of the community. According to the participants, top-notch arts should be widely available, with the particular care and sensitivity for the young people.

\section{PARTICIPANT OPINION ON CULTURE AS A PROMOTER \\ OF INTERCULTURAL DIALOGUE}

Despite the fact that humanity faces daily with a lack of dialogue, three participants have expressed the view that the concept of intercultural dialogue is inadequate because it is obsolete, is no more than just a fashionable phrase. They believe it should be replaced by the term cultural coexistence. Participant, who expressed a negative attitude towards the notion, at the same time stressed the exceptional importance of intercultural dialogue in a globalized world, for which culture has no exclusive right and no responsibility.

Participants from the business world unanimously agreed on the importance of intercultural dialogue for successful business cooperation and coexistence, and recognized culture as a bridge between diverse cultures. They emphasized that successful business practices are those that allow diversity, which build trust on common values and establish dialogue while promoting coexistence and awareness of the importance of providing linguistic diversity for business success. Intercultural dialogue was marked as a way to learn about the values and customs of other nations, or even as the only survival option. Participants from the field of culture and related sectors emphasized the importance of a creative culture of cooperation that connects diverse cultures, since in the intercul- 
tural co-operation a global culture with global phenomena, values and ethics is emerging, it has drawn attention to the wealth of talents brought to society by various individuals and communities and thus enable hybridization and innovation in the field of artistic creation.

\section{Discussion and Future Directions}

Based on the results of the study the following interpretation is given:

1. Culture contributes to sustainable development. It has been unequivocally established that culture contributes to the sustainable development. It is more difficult to accurately determine its concrete effects, because due to the lack of comparable and relevant criteria, we often find ourselves on the slippery ground of justification more based on convictions than concrete indicators. There is a high degree of consensus that culture represents the code of the system of one's own values, while at the same time it acts as a social binder in the community, broadens its horizons, and strengthens the dialogue of openness to difference. Participation in cultural activities promotes creativity and innovation in all fields of operation, improves quality of life, prevails in many areas, and triggers special synergy effects when connecting with other fields.

2. Term cultural capital needs further clarification. Participants understood the concept of cultural capital in two ways, such as the materialization of creativity in cultural heritage and in the acquired skills on the one hand, and the profits from cultural activity on the other.

3. Active participation contributes to social cohesion. It is evident that the accessibility of culture and active participation reinforce the individual's image, enable the way out of the marginal areas to vulnerable groups and individuals, and encourage acceptance. Therefore, culture can also be a powerful factor in the prevention of health and safety. The importance of a culture for social cohesion and the democratization of society are particularly important in times of crisis.

4. Cultural cooperation promotes intercultural dialogue. Cultural cooperation successfully overcomes stereotypes, helps to understand the values and customs of other nations in a spirit of respect and coexistence, and stimulates the promotion of cultural and linguistic diversity, thus developing the intercultural competences of all stakeholders in the dialogue process. Creative intercultural cooperation can link diverse cultures at the symbolic level, help to resolve con- 
flicts between cultures or between subcultures, while at the same time promoting the wealth of talents that diverse individuals and communities bring to society, enables hybridization and innovation in the field of artistic creation.

5. Systemic solution is needed. The study confirms the contribution of the cultural and creative sectors and related sectors for economic development. The contribution to culture represents an investment in sustainable development and the stimulation of self-confidence and the innovative entrepreneurship of its citizens on the other hand. However, the potential for creative partnerships between creators and the economy in comparison with the international space in Slovenia remain underused.

6. Paradigm change is needed. To change the paradigm, both political will and qualification of the political decision makers are needed. It is only in view of both aspects that it would be possible to restore the fragile confidence of the cultural and creative sector and to establish stronger partnerships with it.

Based on the results of the study the following six future directions for policy makers are proposed:

1. Integrate culture into sustainable development strategies and raise awareness of its role by involving all stakeholders.

2. Create partnerships between cultural policy makers and stakeholders. It should be built on mutual trust. Provide financial resources and continuously monitor and evaluate progress.

3. Engage cultural policy makers in overcoming sectoral confusion and promote cross-sectoral cooperation in the fields of education, economy, social affairs, youth policies, development policies and other relevant areas.

4. Establish good practices tailor-made to the needs of stakeholders.

5. Take advantage of the openness and diversity of the natural and cultural heritage of the Slovene territory and offer the pulse of contemporary culture.

6. Empower cultural and creative sector and strengthen its competitiveness.

\section{Conclusion}

Culture can offer answers to global challenges of today's world. The path to cultural sustainability leads through the integration of art and culture 
into all stages of the education process, it is promoted by vibrant contacts with art and heritage and by active participation in cultural projects. Accessibility of culture and participation in it enable individuals to focus on the community, improve self-esteem and at the same time strengthen their responsibility to the community through active citizenship.

Because of its immanent nature, culture encourages and preserves an inclusive, creative and innovative society. The findings of our study affirm the claim about the importance of culture in promotion of sustainable intercultural dialogue. It is necessary to move on from lip service about intercultural dialogue to actually do more in this direction.

Culture, which is a value in itself, also offers a tool for establishing and strengthening intercultural competences. Collaboration in culture makes it possible to open up horizons, discover unknown worlds, learn other cultures, learn languages and make friends. It is the best way to overcome stereotypes and prejudices. The process of intercultural awareness and cooperation is particularly important for young people who will be part of future, hopefuly sustainable society, and therefore special attention should be paid to them.

\section{References}

Apte, S., and J. Sheth. 2016. The Sustainability Edge: How to Drive TopLine Growth with Triple-Bottom-Line Thinking. Toronto: University of Toronto Press.

Brad, S., B. Mocan, E. Brad, and M. Fulea. 2016. 'Environmentally Sustainable Economic Growth.' Amfiteatru Economic 18 (42): 446-6o.

Bueno, E., M. P. Salmador, and O. Rodríguez. 2007. 'The Role of Social Capital in Today's Economy: Empirical Evidence and Proposal of a New Model of Intellectual Capital.' Journal of Intellectual Capital 5 (4): 55674.

Commission of European Communities. 1994. 'On Immigration and Asylum Policies.' сом(94) 23 final, Commission of European Communities, Brussels.

Eberhard, C. 2008. 'Rediscovering Education through Intercultural Dialogue.' Paper presented at the International Meeting of Experts Cultural Diversity and Education UNESCO/UnEsC O Cat, Barcelona, 14-16 January.

Elliott, J. A. 2013. An Introduction to Sustainable Development. London: Routledge.

European Commission. 2001. 'Green Paper: Promoting a European framework for Corporate Social Responsibility'. Commission of the European Communities, Brussels. 
- 2008. 'Council Conclusions of 22 May 2008 on Intercultural Competences.' Official Journal of the European Union C 141/14-16.

- 2009. 'Sustainability Report.' Commission of the European Communities, Brussels.

- 2011. 'A Renewed EU strategy 2011-14 for Corporate Social Responsibility.' $\operatorname{Cом(2011)~} 681$ final, European Commission, Brussels.

- 2012. 'Green Paper: Unlocking the Potential of Cultural and Creative Industries.' http://ec.europa.eu/culture/our -policy-development/doc/GreenPaper_creative_industries_en.pdf

Fantini, A. 2007. 'Exploring Intercultural Competence: Developing, Measuring, and Monitoring.' Research Report 07-01, Washington University, St. Louis, MI.

Frantzeskaki, N., D. Loorbach, and J. Meadowcroft. 2012. 'Governing Societal Transitions to Sustainability'. International Journal of Sustainable Development 15 (1-2): 19-36.

Galletta, A., and W. E. Cross. 2013. Mastering the Semi-Structured Interview and Beyond: From Research Design to Analysis and Publication. New York: New York University Press.

Hasna, A. M. 2007. 'Dimensions of Sustainability'. Journal of Engineering for Sustainable Development: Energy, Environment, and Health 2 (1): 47-57.

Hawkes, J. 2001. The Fourth Pillar of Sustainability: Culture's Essential Role in Public Planning. Melbourne: Cultural Development Network.

Human Rights Council. 2007. 'Promotion of the Enjoyment of the Cultural Rights of Everyone and Respect for Cultural Diversity.' Resolution 6/6. https://ap.ohchr.org/documents/E/HRC/resolutions/A_HRC_RES_6 -6.pdf

Huntington, S. P. 1993. 'The Clash of Civilizations?' Foreign Affairs 72 (3): 22-49.

Joyce, N., L. Vincze, and E. J. Marton. 2016. 'Crossing the Communication Divide: Intergroup Contact and the Desire to Learn the Outgroup's Language.' Journal of International and Intercultural Communication 9 (4): 295-311.

Kates, R. W., T. M. Parris, and A. A. Leserowitz. 2005. 'What is Sustainable Development? Goals, Indicators, Values and Practice.' Environment: Science and Policy for Sustainable Development 47 (3): 8-21.

Kearns, A., and E. Whitley. 2015. 'Getting There? The Effects of Functional Factors, Time and Place on the Social Integration of Migrants.' Journal of Ethnic and Migration Studies 41 (13): 2105-29.

Kordestani, A., K. Peighambari, and T. Foster. 2015. 'Emerging Trends in Sustainability Research: A Look Back as We Begin to Look Forward.' International Journal of Sustainable Development 14 (2): 154-69. 
Larsen, C. A. 2014. Social Cohesion: Definition, Measurement and Developments. Aalborg: Aalborg University.

Lee, N. A. 2016. Sustainable Development and Complexity Science. N.p.: Amazon Digital Services.

Li, R. Y. M., and D. H. A. Pak. 2010. 'Resistance and Motivation to Share Sustainable Development by Web 2.o.' Journal of Information \& Knowledge Management 9 (3): 251-62.

Makarov, P. 2010. 'Intellectual Capital as an Indicator of a Sustainable Development.' Journal of Sustainable Development 3 (3): 85-9o.

Marrion, C. E. 2016. 'More Effectively Addressing Fire/Disaster Challenges to Protect Our Cultural Heritage.' Journal of Cultural Heritage 20 (7-8): 746-49.

Mulunga, S. N., and R. Yazdanifard. 2014. 'Review of Social Inclusion, Social Cohesion and Social Capital in Modern Organization.' Global Journal of Management and Business Research: Administration and Management 14 (3): 14-20.

oECD. 2011. Divided We Stand: Why Inequality Keeps Rising. Paris: Organization for Economic Cooperation and Development.

Sachs, J. 2015. The Age of Sustainable Development. New York: Columbia University Press.

Sage, D. 2013. 'Are More Equal Societies the Most Cohesive?' International Journal of Sociology and Social Policy 33 (11-12): 640-57.

Savitz, A. W. 2014. The Triple Bottom Line. San Francisco, C A: Jossey Bass.

Schoefthaler, T. 2006. 'Challenges in Assuring Dialogue between Cultures.' Presented at the forum Europe in Dialogue and Interaction between Cultures, Helsinki, 5 April.

Segalas, J., D. Ferrer-Balas, M. Svanstrom, U. Lundqvist, and K. F. Mulder. 2009. 'What Has To Be Learnt for Sustainability? A Comparison of Bachelor Engineering Education Competences at Three European Universities.' Sustainability Science 4 (1): 17-27.

Shaharir, B. M. Z. 2012. 'A New Paradigm of Sustainability'. Journal of Sustainable Development 5 (1): 91-99.

Singer, M. 2010. 'Eco-Nomics: Are the Planet-Unfriendly Features of Capitalism Barriers to Sustainability?' Sustainability 2 (1): 127-44.

Støvring, K. 2012. 'The Cultural Prerequisites of Social Cohesion: With Special Attention to the Nation of Denmark.' International Journal of Sociology and Social Policy 32 (3-4): 134-52.

Throsby, D. 1999. 'Cultural Capital.' Journal of Cultural Economics 23 (1-2): 3-12.

- 2001. Economics and Culture. Cambridge: Cambridge University Press. 
Tylor, E. 1871. Primitive Culture: Research into the Development of Mythology, Philosophy, Religion, Art, and Custum. London: Murray.

Ucok-Sayrak, O. 2016. 'Attending to the "Face of the Other" in Intercultural Communication: Thinking and Talking about Difference, Identity, and Ethics.' Journal of International and Intercultural Communication 9 (2): 122-39.

UnesCo. 1998. 'Intergovernmental Conference on Cultural Policies for Development.' https://unesdoc.unesco.org/ark:/48223/pfoooo113935

—. 2001. 'Universal Declaration on Cultural Diversity'. http://www .unesco.org/new/fileadmin/MULTIMEDIA/HQ/CLT/pdf/5_Cultural _Diversity_EN.pdf

- 2005. 'Convention on the Protection and Promotion of the Diversity of Cultural Expressions.' http://www.unesco.org/new/en/culture/ themes/culturaldiversity/diversity-of-cultural-expressions/the -convention/convention-text/.

- 2010. Resolution A/65/438 and Resolution 66/208. Culture and Development. http://www.cultura21.net/wp-content/uploads/2012/o6/ UNGA-66-208-EN.pdf

- 2013. 'The Hangzou Declaration. Placing Culture at the Heart of Sustainable Development Policies.' http://www.unesco.org/new/ fileadmin/MULTIMEDIA/HQ/CLT/images/

FinalHangzhouDeclaration20130517.pdf

United Nations. 2012. Resolution adopted by the General Assembly on 27 July 2012 (A/66/L.56)] 66/288. https://www.un.org/en/development/ desa/population/migration/generalassembly/docs/globalcompact/A _RES_66_288.pdf

United Nations World Commission on Environment and Development. 1987. Our Common Future. Oxford: Oxford University Press.

Utting, P. 200o. Business Responsibility for Sustainable Development. Geneva: United Nations Research Institute for Social Development.

Wells, J. C., and L. Lixinski. 2016. 'Heritage Values and Legal Rules: Identification and Treatment of the Historic Environment via an Adaptive Regulatory Framework.' Journal of Cultural Heritage Management and Sustainable Development 6 (3): 345-64.

Yarbrough, D. 2011. 'Interfaith Dialogue in the Pulpit - Proclaiming an Emerging Gospel.' Journal of Interreligious Studies 6:15-19.

Yencken, D., and D. Wilkinson. 2000. Resetting the Compass: Australia's Journey towards Sustainability. Collingwood: csiro Publishing. Yin, R. 1984. Case Study Research. Beverly Hills, CA: Sage. 